\title{
Gypsum polymer materials in construction
}

\author{
Igor Bessonov ${ }^{1, *}$, Aleksey Zhukov ${ }^{1,2}$ Boris Efimov ${ }^{2}$; Elina Gorbunova ${ }^{1,2 *}$, and Ilya \\ Govryakov ${ }^{1,2}$ \\ ${ }^{1}$ Research Institute of Building Physics of the Russian Academy of Architecture and Building, \\ 127238, Lokomotivny pr. 21, Moscow, Russia \\ ${ }^{2}$ Moscow State University of Civil Engineering, 129337 Yaroslavskoye av. 26, Moscow, Russia
}

\begin{abstract}
The modern level of technological development involves the use of traditional materials modified with additives of various types and functional purposes, as well as composite materials allowing to obtain a product with improved properties. Expanding the area of application of products based on gypsum for facade systems involves the creation of weather-resistant, and, first of all, waterproof materials based on gypsum polymers. The purpose of the experiment, the results of which are presented in the article, was to assess the possibility of using polycondensation polymers as a component of gypsum polymer, to model the properties of the material and to evaluate its characteristics as a result of climatic and humidity influences. The modeling and optimization of gypsum polymer properties were based on statistical methods as well as methods of mathematical analysis of functions of several variables. The assessment of the water resistance of gypsum polymer samples was carried out under test conditions in an open reservoir with an almost unlimited reaction capacity of the medium. The weather resistance was checked according to the results of tests in a climatic chamber. Experiments have shown that the strength of samples with $20 \%$ modified melamineformaldehyde resin in compression and in bending for 80 days of storage in air increases by $30 \%$ and $25 \%$, respectively. The compressive strength is $60 \mathrm{MPa}$, and the flexural strength is $12 \mathrm{MPa}$. Gypsum polymer has high frost resistance up to 150 cycles of alternate freezing and thawing. The result of the research was the confirmation of the possibility of using polycondensation resins and the foundations of the method for selecting the composition of the gypsum polymer were developed. The results obtained can be used in the development of the technology of gypsum polymer products, and, in particular, piece products (building cladding tiles).
\end{abstract}

\section{Introduction}

The traditional application area of gypsum products is indoor work. For the construction of facings and partitions, frame systems or foam gypsum blocks are used; decorative and acoustic materials based on gypsum are widely used in suspended ceilings; when decorating premises, gypsum plaster compositions are widely used. Gypsum materials not

*Corresponding author: *bessonoviv@mail.ru 
only make it possible to create interiors, but also contribute to the formation of the microclimate of the premises as a whole, i.e. create comfortable conditions for people [13]. Gypsum plasterboard or gypsum fiber sheets, stucco decorations, self-leveling floors, various dry plaster, putty and glue gypsum mixtures. suspended ceiling panels and etc. are used in the interior decoration.

Studying the historical buildings of big cities, estates, buildings of the XVII-XIX centuries, you can see gypsum-containing materials not only in the interiors, but also on the facades of buildings. These decorative stucco architectural decorations were made mainly of gypsum-lime mortar, treated with lye or vitriol and repeated impregnation with hot linseed oil.

Many researchers have proposed a method for increasing the water resistance of gypsum by introducing additives that have a common ion with calcium sulfate (for example lime), which reduces its solubility [4-6], or blast furnace slags.

Later gypsum-cement-puzzolanic (GCP) and gypsum-slag-cement-pozzolanic (GSCP) binders were created and comprehensively studied, new technologies were developed for obtaining waterproof gypsum binders. CGB - composite gypsum binders and WGLW waterproof gypsum binders of low water demand [7-9].

The use of secondary products from other industries, and, in particular, modified phosphogypsum, finely dispersed compositions and clay gypsum also make it possible to obtain products with increased water resistance [10-14].

Hydrophobization can be superficial and volumetric. Superficial treatment with water repellents tends to lose its effeciency over time, and for a longer use of the sheets, it must be repeated periodically. The frequency of treatment with water repellents depends on the operational conditions of the products. Taking into account the experience in the research, a method was adopted for modifying the gypsum binder with various polymers in the form of aqueous solutions or emulsions. The influence of the type of polymer and its consumption on the properties of the composite was studied, as well as the influence of temperature and humidity conditions on these properties.

Note that the use of products based on a modified gypsum binder in facade systems is directly related to the development of a method for assessing the weather resistance of this material, and, first of all, water resistance and frost resistance.

\section{Methods}

In the course of the work, the effect of various polymers in the form of aqueous solutions or emulsions on the properties of the composite was studied. The best results were obtained when using polycondensation aminoaldehyde resins with non-linear monomers (melamine, resorcinol, benzoguanamine).

The experiment to assess the influence of the gypsum polymer composition on its properties was carried out according to the general methodology for planning the experiment and analytical optimization of its results [15-17], based on the matrix of a full quadratic three-factor experiment. The resulting regression equations were tested against all statistical hypotheses. On the fact of comparison with confidence intervals $(\Delta \mathrm{bj})$, only significant factors were left, and as a result of verification by Fisher's criterion, a conclusion was made about the adequacy (or inadequacy) of the obtained models.

In the study of the water resistance and atmosphere resistance of gypsum polymer samples, the conditions of exposure to the medium samples in an open reservoir were simulated with an almost unlimited reaction capacity of the medium. The atmosphere resistance of the products was assessed based on the results of testing their properties after processing in a climatic chamber. 
Along with conducting frost resistance tests on cube samples, the consequences of cyclic climatic influences on the products themselves were studied. The research was carried out in a cooling and sprinkling installation «Thermal insulation KhDU-0.2», equipped with a swivel holder, into which the investigated element of the facade cladding is installed. The control is carried out both visually and with the use of the «Onyx-2.3» device intended for the control of surface strength by the non-destructive shock-pulse method.

\section{Results}

The experiment was built on the basis of mathematical planning methods and statistical processing of its results. The following factors are accepted as variable factors: the strength of the gypsum binder $\left(\mathrm{X}_{1}\right)$, the consumption of melamine-formaldehyde resin $\left(\mathrm{X}_{2}\right)$ and the consumption of the structuring additive $\left(\mathrm{X}_{3}\right)$. The strength of the gypsum polymer after 7 days of specimen hardening $\left(\mathrm{Y}_{1}\right)$ was taken as a response function, and the softening coefficient of the gypsum polymer specimens was taken as the optimization parameter according to the results of climatic tests $\left(\mathrm{Y}_{2}=\mathrm{Y}_{1} / \mathrm{R}_{\mathrm{w}}\right)$. Experimental conditions are shown in Table 1.

Table 1. Intervals of variation of factors.

\begin{tabular}{|c|c|c|c|c|c|}
\hline Factor name & Symbol $\mathrm{X}_{\mathrm{i}}$ & $\begin{array}{c}\text { Average } \\
\text { value of the } \\
\text { factor, } \\
\overline{\mathrm{X}}_{\mathrm{i}}\end{array}$ & $\begin{array}{c}\text { Variation } \\
\text { interval, } \\
\Delta \mathrm{X}_{\mathrm{i}}\end{array}$ & \multicolumn{2}{|c|}{$\begin{array}{c}\text { Factor values at } \\
\text { levels }\end{array}$} \\
\cline { 3 - 6 } & $\mathrm{X}_{1}$ & 6 & 1 & -1 & +1 \\
\hline $\begin{array}{c}\text { Gypsum strength, } \\
\mathrm{MPa}\end{array}$ & $\mathrm{X}_{2}$ & 17 & 4 & 13 & 7 \\
\hline $\begin{array}{c}\text { Resin } \\
\text { consumption, } \%\end{array}$ & $\mathrm{X}_{3}$ & 3 & 1 & 2 & 4 \\
\hline $\begin{array}{c}\text { Consumption of } \\
\text { structuring } \\
\text { additive, } \%\end{array}$ & & & & & 21 \\
\hline
\end{tabular}

Mathematical processing of the results of the experiment made it possible to obtain the regression equations for the compressive strength of gypsum polymer samples $\left(\mathrm{Y}_{1}\right)$ and its softening coefficient $\left(\mathrm{Y}_{2}\right)$. The significance of the coefficient was checked by confidence intervals; accordingly, the confidence interval for strength was $\Delta b_{1}=1 \mathrm{MPa}$, and the softening coefficient was $\Delta b_{2}=0.04$.

The resulting models were tested for adequacy by Fisher's criterion. The calculated values of Fisher's criteria are equal for the model of compressive strength $F_{1}=16.2$ and for the model for the softening coefficient $F_{2}=15.9$ and less than the table values, therefore the models are considered adequate.

The following mathematical models (polynomials) are obtained:

- for compressive strength

$$
\mathrm{Y}_{1}=54+15 \mathrm{X}_{1}+7 \mathrm{X}_{2}+6 \mathrm{X}_{3}+3 \mathrm{X}_{1} \mathrm{X}_{2}+2 \mathrm{X}_{1} \mathrm{X}_{3}
$$

- for the softening coefficient:

$$
\mathrm{Y}_{2}=0.82+0.08 \mathrm{X}_{1}+0.14 \mathrm{X}_{2}+0.09 \mathrm{X}_{3}-0.04 \mathrm{X}_{1} \mathrm{X}_{2}-0.05 \mathrm{X}_{3}^{2}
$$

\section{Discussion}

Analysis of the coefficients of the equation $\mathrm{Y}_{1}=f_{1}\left(\mathrm{X}_{1}, \mathrm{X}_{2}, \mathrm{X}_{3}\right)$ shows that the strength of the gypsum polymer increases with increasing values of all factors (in the areas of their 
definition). The strength of the gypsum binder (its brand) has the greatest effect on strength. The softening factor is more dependent on the resin consumption.

Analytical optimization is based on the fact that the functions for strength and density $\mathrm{Y}_{1}=f_{1}\left(\mathrm{X}_{1}, \mathrm{X}_{2}, \mathrm{X}_{3}\right)$ and $\mathrm{Y}_{2}=f_{2}\left(\mathrm{X}_{1}, \mathrm{X}_{2}, \mathrm{X}_{3}\right)$ are mathematical and methods of mathematical analysis can be applied to them, provided that there is no the condition of adequacy is violated. In the case under consideration, the following scheme is adopted:

- the equation $\mathrm{Y}_{2}=f_{2}\left(\mathrm{X}_{1}, \mathrm{X}_{2}, \mathrm{X}_{3}\right)$ is differentiated by $\mathrm{X}_{3}$ and equated to zero, determining the extremum of the function $\mathrm{Y}_{2}$ by $\mathrm{X}_{3}$;

- solve the functions $\mathrm{Y}_{1}=f_{1}\left(\mathrm{X}_{1}, \mathrm{X}_{2}, \mathrm{X}_{3}\right)$ and $\mathrm{Y}_{2}=f_{2}\left(\mathrm{X}_{1}, \mathrm{X}_{2}, \mathrm{X}_{3}\right)$ with $\mathrm{X}_{3}=\mathrm{opt}$ and carry out local optimization.

Analytical optimization includes the following sequence of actions:

1) Determine the value of the local extremum of the function $Y_{2}=f_{1}\left(X_{1}, X_{2}, X_{3}\right)$ by $X_{3}$ :

$$
\frac{\partial \mathrm{y}_{2}}{\partial \mathrm{X}_{\mathrm{s}}}=0.09-0.10 \mathrm{X}_{3}=0 \rightarrow \mathrm{X}_{3}=\frac{0.09}{0.1}=0.9
$$

2) We calculate the value of the natural value of the plasticizer consumption (corresponding to the possible obtaining of the maximum compressive strength of polymer concrete), using the deciding factor formula and the experimental conditions (Table 1):

$$
\widetilde{\mathrm{X}}_{3}=\overline{\mathrm{X}}_{3}+\Delta \mathrm{X}_{3} \cdot 0.9=3+1 \cdot 0.9=3.9 \mathrm{~kg} / \mathrm{m}^{3}
$$

3) We calculate mathematical models (polynomials) for the optimized value of the factor $\mathrm{X}_{3}=0.9$ :

- for compressive strength:

$$
\mathrm{y}_{1}=59+17 \mathrm{X}_{1}+7 \mathrm{X}_{2}+3 \mathrm{X}_{1} \mathrm{X}_{2}
$$

- for the softening coefficient:

$$
\mathrm{y}_{2}=0.86+0.08 \mathrm{X}_{1}+0.14 \mathrm{X}_{2}-0.04 \mathrm{X}_{1} \mathrm{X}_{2}
$$

The graphic interpretation of the obtained models is shown in figure 1.and figure 2 and can be used when designing a gypsum polymer composition.

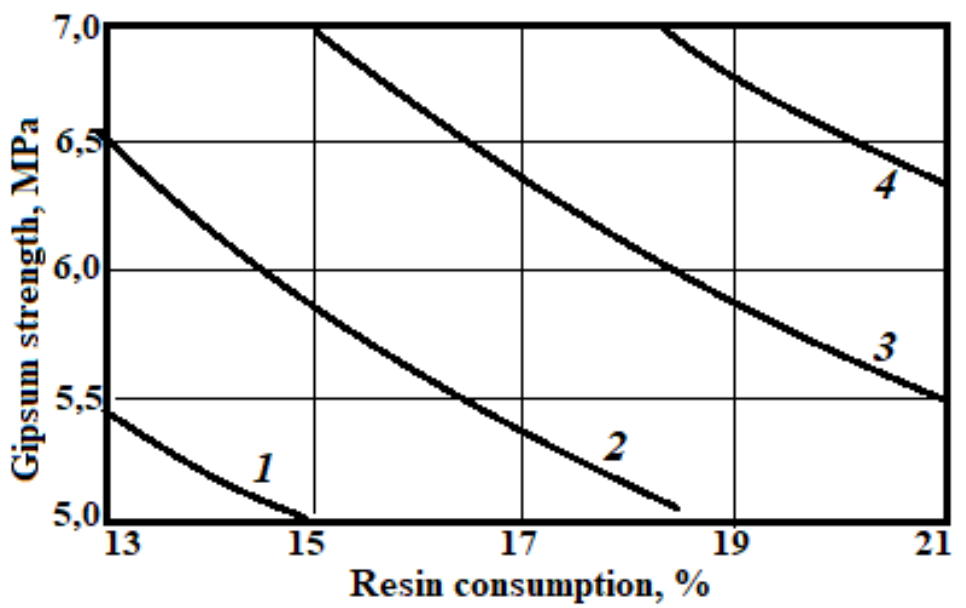

Fig. 1. Dependence of compressive strength on variable factors at an optimized consumption of a structuring additive of $3.9 \mathrm{~kg} / \mathrm{m} 3$. Compressive strength: 1 - $45 \mathrm{MPa} ; 2$ - $50 \mathrm{MPa}$; 3 - $55 \mathrm{MPa}$; 4 - $60 \mathrm{MPa}$. 
In the course of research, it was determined that the strength of samples with $20 \%$ modified melamine-formaldehyde resin in compression and in bending for 80 days of storage in air increases by $30 \%$ and $25 \%$, respectively. The compressive strength is 60 $\mathrm{MPa}$, and the flexural strength is $12 \mathrm{MPa}$. Gypsum polymer has a fairly high frost resistance. Samples with $20 \%$ melamine-formaldehyde resin withstand 150 cycles of alternate freezing and thawing.

In the study of the water resistance and atmosphere resistance of gypsum polymer samples, the conditions of exposure to the medium samples in an open reservoir were simulated with an almost unlimited reaction capacity of the medium.

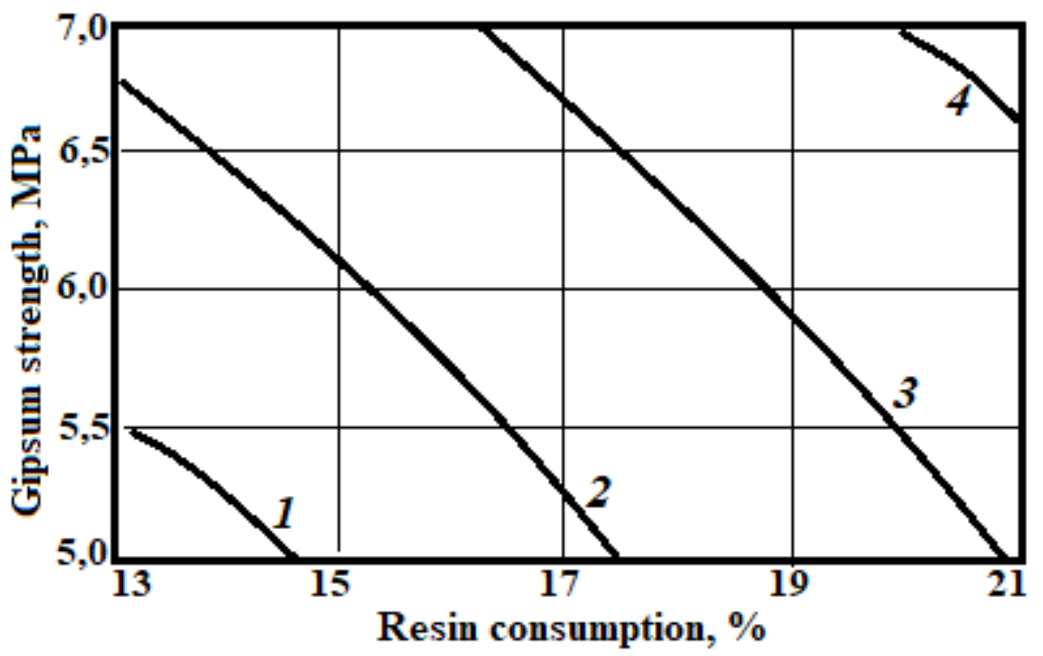

Fig. 2. Dependence of the softening coefficient on variable factors at an optimized consumption of a structuring additive of $3.9 \mathrm{~kg} / \mathrm{m} 3$. Softening factor: $1-0.7 ; 2-0.8 ; 3-0.9 ; 4-1.0$.

It has been established that the depth of destruction of gypsum polymer samples in distilled water significantly decreases with an increase in the density of the hardened stone due to an increase in the content of the polymer component and a decrease in the watergypsum ratio. The best results were obtained using modified melamine-formaldehyde resin.

With constant immersion of samples in distilled water, the strength of gypsum polymer with $20 \%$ modified melamine-formaldehyde resin in 8 months of testing decreased by only $20 \%$, and for control gypsum samples during the same time - by $70 \%$. Under the conditions of alternating moistening and drying during the same test time, the strength of gypsum polymer samples practically did not change, and for gypsum samples it decreased by $70 \%$.

With increasing age of the samples, no significant changes in the characteristics of the composite occur. The increase in strength over time can be explained by the continued polymerization of the resin. The degree of polymerization of the resin in the presence of a hardener under natural conditions is practically the same as during heat treatment.

The vapor permeability of the gypsum polymer is $0.092 \mathrm{mg} /(\mathrm{m} . \mathrm{h} . \mathrm{Pa})$, which determines a favorable humidity regime for walls made of brickwork with facing from this material. The durability of the exterior decoration with modified plaster products is confirmed by practice. Currently, architectural and decorative products made of gypsum polymer decorate the facades of buildings in Moscow, Nizhny Novgorod, Perm. The properties of gypsum polymer make it possible to use it from small plastic products with a fine relief to volumetric landscape gardening sculptures. 


\section{Conclusions}

The studies carried out made it possible to determine the optimal consumption of polycondensation resin and finely ground mineral additives, and also allowed the development of important elements for the formation of a method for selecting a gypsum polymer composition. The possibility of using polycondensation resins in a composition with a gypsum binder has been confirmed.

The strength of samples with $20 \%$ modified melamine-formaldehyde resin in compression and in bending for 80 days of storage in air increases by $30 \%$ and $25 \%$, respectively. The compressive strength is $60 \mathrm{MPa}$, and the flexural strength is $12 \mathrm{MPa}$. Gypsum polymer has a fairly high frost resistance. Samples with $20 \%$ melamineformaldehyde resin withstand 150 cycles of alternate freezing and thawing.

The results obtained can be used in the development of the technology of gypsum polymer products, and, in particular, piece products (tiles) for facing the facades of buildings. The vapor permeability of the gypsum polymer is $0.092 \mathrm{mg} /$ (m.h.Pa), which determines the favorable humidity regime of the walls made of brickwork with facing from this material.

\section{References}

1. E. V. Korolev, A. M. Danilov, I. A. Garkina, Building Materials 7, 55-57 (2006)

2. A. F. Buryanov, Building Materials 9, 46-48 (2005)

3. A. I. Panchenko, A. F. Buryanov, N. V. Kozlov, et al., Building Materials 12, 72-74 (2014)

4. I. V. Bessonov, 3 Scientific-practical Conf. "Problems of construction thermal physics and energy saving in buildings", Sat. report, NIISF, 112-117 (1998)

5. M. S. Garkavi, A. F. Bur'yanov, H. B. Stroitel'nye Materialy 12, 73-75 (2015)

6. I. V. Bessonov, O. V. Yalunina, Construction Materials Magazine 4, 10-12 (2004)

7. A.V. Ferronskaya, V. F. Korovyakov, S. V. Melnichenko, L. D. Chumakov, Building materials 5, 34-35 (1992)

8. A. P. Pustovgar, A. F. Burianov, P. G. Vasilik, Stroitelnye Materialy 12, 61-64 (2010)

9. M. O. Asamatdinov, A. A. Medvedev, A. D. Zhukov, et al., Web of Conferences (2018) DOI: https://doi.org/10.1051/matecconf/201819303045

10. T. E. Khaev, E. V. Tkach, D. V. Oreshkin, Building Materials 10, 45-51 (2017)

11. M-B. Kh. Kodzoev, S. L. Isachenko, et al., MATEC Web of Conferences 170, 03022 (2018) DOI: https://doi.org/10.1051/matecconf/201817003022

12. Yu. G. Meshheryakov, S. V. Fedorov, Industrielle verarbeitung von Phosphogips and Phospho Energiesparende technologien, 141 (Int. Kongress Fachmesse Euro ECO, Hannover, 2008)

13. G. Yakovlev, I. Polyanskikh, G. Fedorova, et al., Procedia Engineering "7th Scientific Technical Conference Material Problems in Civil Engineering" 108, 13 - 21 (2015)

14. M. Bekmanssurov, A. Gordina, I. Poljanskich, et al., 19 Internationale Baustofftagung, 16-18 September, Weimar, Bauhaus, 2, 645-651 (2015)

15. I. Bessonov, A. Zhukov, E. Shokodko, A. Chernov, E3S Web of Conferences 164, 14016 (2020) DOI: https://doi.org/10.1051/e3sconf/202016414016

16. A. Zhukov, E. Shokodko, E. Bobrova, et al., Advances in Intelligent Systems and Computing 983, 740-747 (2019) DOI: 10.1007/978-3-030-19868-8_72 
17. A. Zhukov, E. Shokodko, Advances in Intelligent Systems and Computing 1116, 413421 (2020) DOI: https://doi.org/10.1007/978-3-030-37919-3_40 